03

\title{
Исследование аэродинамических характеристик вращающихся цилиндров, расположенных параллельно друг другу
}

\author{
(c) Н.К. Танашева, ${ }^{1}$ Б.Р. Нусупбеков, ${ }^{2}$ А.Н. Дюсембаева, ${ }^{2}$ Н.Н. Шуюшбаева ${ }^{3}$ \\ ${ }^{1}$ Институт прикладной математики, \\ 100028 Караганда, Казахстан \\ ${ }^{2}$ Карагандинский государственный университет им. акад. Е.А. Букетова, \\ 100028 Караганда, Казахстан \\ ${ }^{3}$ Кокшетауский государственный университет им. Ш. Уалиханова, \\ 020000 Кокшетау, Казахстан \\ e-mail: nazgulya_tans@mail.ru
}

Поступило в Редакцию 27 ноября 2018 г.

В окончательной редакции 27 ноября 2018 г.

Принято к публикации 19 января 2019 г.

\begin{abstract}
Приведены результаты экспериментальных исследований по определению коэффициента лобового сопротивления и коэффициента подъемной силы систем вращающихся цилиндров, расположенных параллельно друг другу. Результаты показали, что при росте расстояния между вращающимися цилиндрами уменьшаются коэффициент лобового сопротивления и коэффициент подъемной силы. Экспериментально установлено, что расстояние, начиная с которого влияние цилиндров друг на друга практически исчезает, составляет 0.4 диаметра исследуемых цилиндров.
\end{abstract}

DOI: $10.21883 / J T F .2019 .07 .47788 .415-18$

\section{Введение}

Современный уровень развития техники и высоких технологий позволяет использовать вращающийся цилиндр как особый элемент для получения дополнительной подъемной силы, направленной поперек потока. При вращательном движении цилиндра в потоке воздуха в верхней части цилиндра скорость потока и скорость поверхности совпадают, они складываются, и появляется ускорение потока и повышение скорости [1]. В нижней части цилиндра скорости потока и вращающейся поверхности направлены противоположно, они вычитаются, происходит торможение и уменьшение скорости [2-4]. Появление такой разницы скоростей приводит к появлению поперечной разницы давлений и возникновению поперечной подъемной силы (эффект Магнуса). Данное явление нами использовано для создания ветродвигателя.

Использование эффекта Магнуса при вращении цилиндра в потоке известно давно, однако возможность его практического использования в качестве движущей силы ветродвигателей нового поколения для малых скоростей потока систематизировано изучается только в последние годы.

Целью настоящей работы является исследование на основе эффекта Магнуса, аэродинамических характеристик вращающихся цилиндров, расположенных параллельно друг другу.

Ранее были проведены исследования зависимостей аэродинамических характеристик вращающихся цилиндров от угла скоса воздушного потока [5].

\section{Методика исследования}

Экспериментальные исследования проводились в научной лаборатории аэродинамических измерений кафедры инженерной теплофизики им. профессора Ж.С. Акылбаева. Был собран опытный макет из двух вращающихся цилиндров, расположенных параллельно друг другу, работающий на основе эффекта Магнуса, который в последующем исследовался в поперечном потоке воздуха, обладающем различными скоростями. Макет устанавливается в рабочей части аэродинамической трубы Т-1-М, прикрепленной с помощью тонких металлических растя-

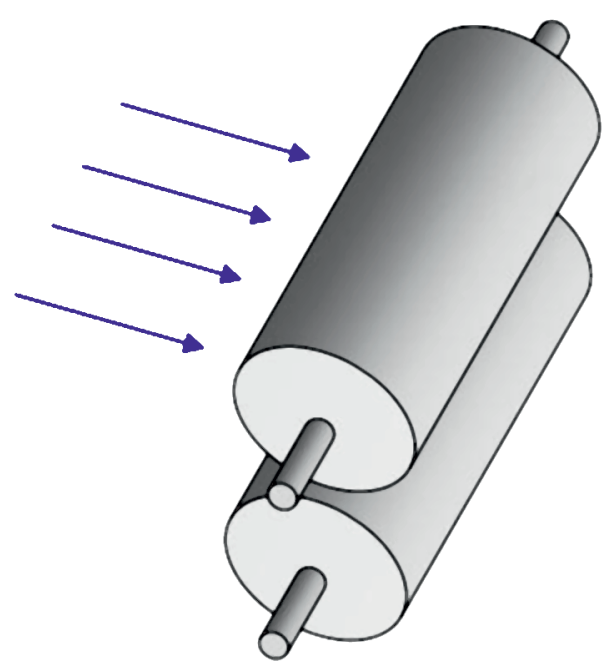

Рис. 1. Схема расположения параллельных друг другу двух вращающихся цилиндров. 


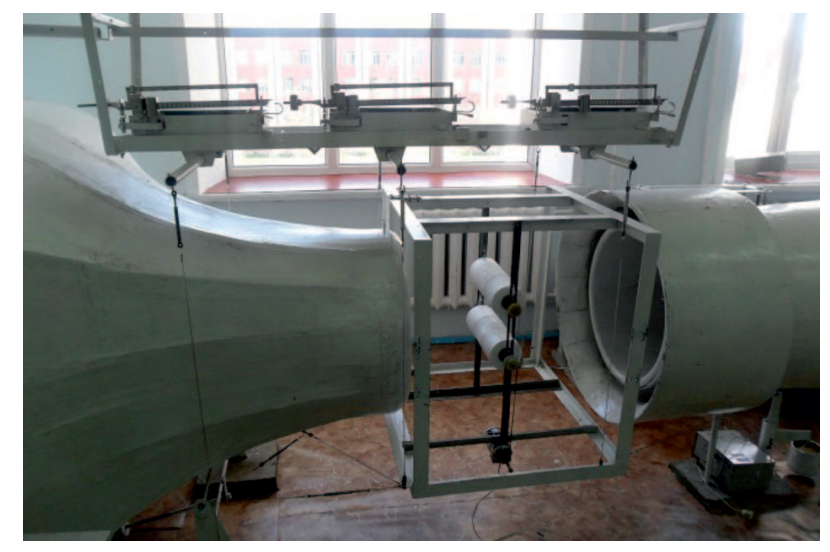

Рис. 2. Общий вид рабочей части аэродинамической трубы с установленными для исследования вращающимися цилиндрами.

жек к раме трехкомпонентных аэродинамических весов. Трехкомпонентные аэродинамические весы с достаточно высокой степенью точности позволяют измерять силу лобового сопротивления и подъемную силу.

Для изучения системы вращающихся цилиндров нами были проведены экспериментальные исследования аэродинамических параметров из двух вращающихся цилиндров, расположенных параллельно друг другу.

На рис. 1 и 2 представлены схема расположения двух параллельных друг другу вращающихся цилиндров, в которой поток воздуха, набегая на лобовую часть цилиндра, прикладывает силу, и эта сила отражается на весах, а также общий вид рабочей части аэродинамической трубы с установленным для исследования экспериментальным макетом.

Испытания проводились с двумя вращающимися цилиндрами диаметром $100 \mathrm{~mm}$, скорость воздушного потока менялась от 5 до $10 \mathrm{~m} / \mathrm{s}$. При этом скорость набегающего потока и частота вращения цилиндров оставались неизменными.

Лабораторные исследования проводились при расстояниях между цилиндрами от 0.5 до $10 \mathrm{~cm}$.

При исследовании аэродинамических характеристик двух вращающихся цилиндров были рассмотрены два случая:

- оба цилиндры вращаются в одну сторону против потока воздуха;

- цилиндры вращаются противоположно друг другу.

Для расчета коэффициента лобового сопротивления $C_{x}$ и коэффициента подъемной силы в ходе выполнения работы использовались формулы (1) и (2):

$$
\begin{aligned}
& C_{y}=\frac{\Delta F_{y}}{\rho \frac{u^{2}}{2} S}, \text { или } C_{y}=\frac{2 F_{y}}{\rho u^{2} S} . \\
& C_{x}=\frac{\Delta F_{x}}{\rho \frac{u^{2}}{2} S}, \quad \text { или } \quad C_{x}=\frac{2 F_{x}}{\rho u^{2} S} .
\end{aligned}
$$

Здесь $C_{y}-$ коэффициент подъемной силы; $C_{x}-$ коэффициент лобового сопротивления; $\Delta F_{x}-$ сила лобового сопротивления, $[\mathrm{N}] ; \Delta F_{y}-$ подъемная сила, $[\mathrm{N}]$; $\rho$ - плотность воздуха, $\left[\mathrm{kg} / \mathrm{m}^{3}\right] ; u-$ скорость потока воздуха, $[\mathrm{m} / \mathrm{s}] ; S-$ площадь миделевого сечения, $\left[\mathrm{m}^{2}\right]$.

\section{Результаты исследования}

По полученным результатам исследований аэродинамических сил рассчитаны и построены графики зависимости коэффициента лобового сопротивления и коэффициента подъемной силы от расстояния между цилиндрами $L$.

На рис. 3 представлен график зависимости коэффициента лобового сопротивления от расстояния между цилиндрами, вращающимися в одном направлении.

С увеличением расстояния между цилиндрами до $3 \mathrm{~cm}$ коэффициент силы лобового сопротивления увеличивается, но с дальнейшим увеличением расстояния (с 3 до $4 \mathrm{~cm})$ значения коэффициента лобового сопротивления постепенно уменьшается с 2.3 до 1.4. При дальнейшем увеличении расстояния между цилиндарми их взаимовлияние практически исчезает.

На рис. 4 представлен график зависимости коэффициента подъемной силы от расстояния между цилиндрами,

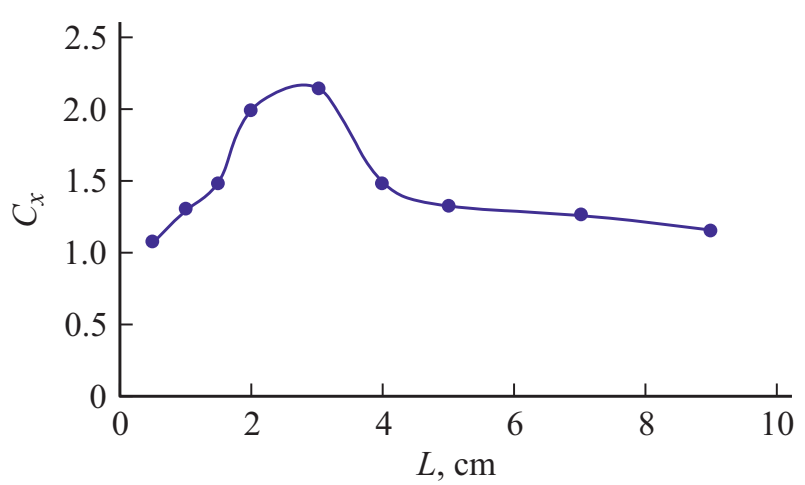

Рис. 3. Зависимость коэффициента лобового сопротивления от расстояния между цилиндрами, вращающимися в одном направлении.

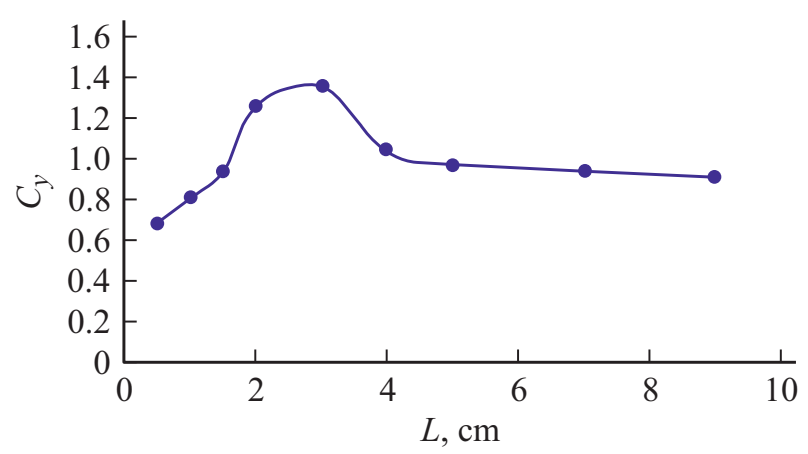

Рис. 4. Зависимость коэффициента подъемной силы от расстояния между цилиндрами, вращающимися в одном направлении. 


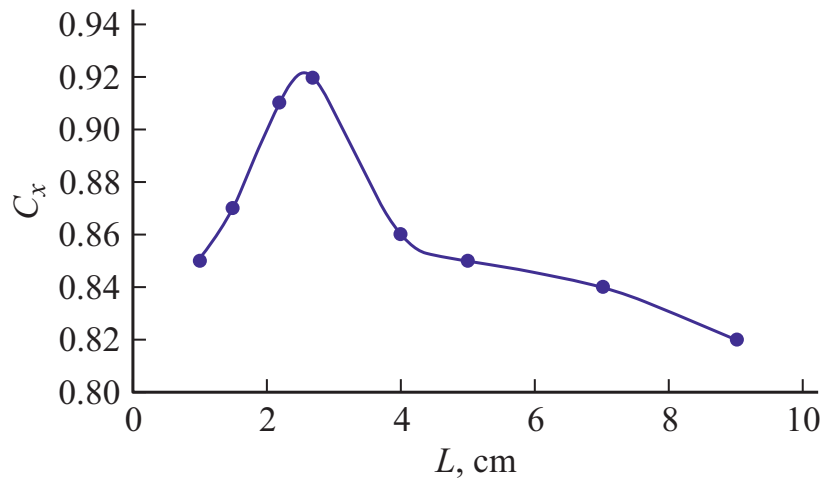

Рис. 5. Зависимость коэффициента лобового сопротивления от расстояния между цилиндрами, вращающимися в противоположных направлениях.

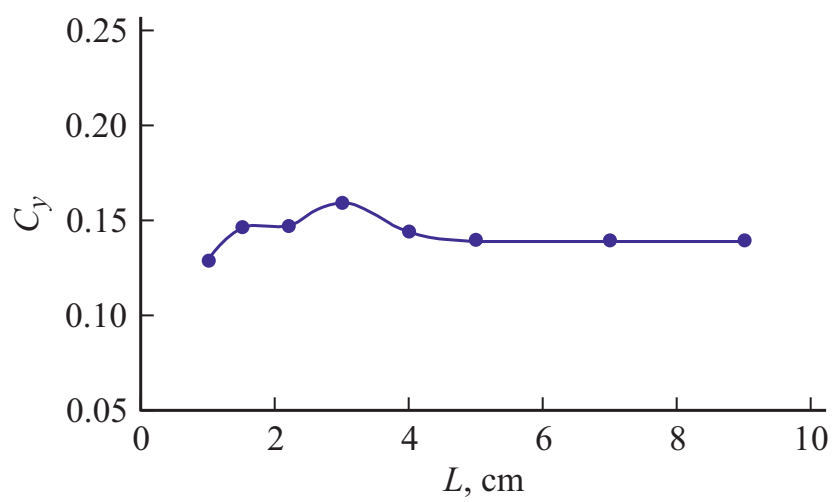

Рис. 6. Зависимость коэффициента подъемной силы от расстояния между цилиндрами, вращающимися в противоположных направлениях.

вращающимися в одном направлении. Из рисунка видно, что с увеличением расстояния между цилиндрами до $3 \mathrm{~cm}$ коэффициент подъемной силы растет. При дальнейшем увеличении расстояния от 3 до $4 \mathrm{~cm}$ значение коэффициента подъемной силы постепенно уменьшается с 1.3 до 1. Далее с увеличением расстояния от $4 \mathrm{~cm}$ и выше взаимовлияние цилиндров исчезает.

Далее представлены уникальные графики зависимостей коэффициента лобового сопротивления и коэффициента подъемной силы цилиндров от расстояния между цилиндрами, вращающимися в противоположных направлениях (рис. 5, 6). В этом случае возникающие в следе за вращающимися цилиндрами вихри будут приближаться друг к другу, затем сливаться, как бы создавая область, похожую на хорошо обтекаемое тело.

Из полученных графиков (рис. 5 и 6) мы видим, что в отличие от цилиндров, вращающихся в одном направлении, противоположно вращающиеся цилиндры практически не создают подъемную силу, так как с увеличением расстояния между цилиндрами значение коэффициента подъемной силы практически не возрастает и не уменьшается. При дальнейшем увеличении расстояния взаимовлияние цилиндров практически исчезает.

\section{Заключение}

На основе полученных данных можно сделать следующие выводы:

- оптимальным вариантом являются противоположно вращающиеся цилиндры при расстоянии между ними $3 \mathrm{~cm}$.

- расстояние, начиная с которого взаимовлияние цилиндров друг на друга практически исчезает, составляет $4 \mathrm{~cm}$ или 0.4 диаметра исследуемых цилиндров. Это расстояние, как правило, устанавливается для любой исследуемой системы цилиндров экспериментальным путем.

В отличие от существующих методов данный подход основан на активном захвате потока воздуха вращающимися цилиндрическими элементами. Постоянство сечения обеспечивает вращающимся элементам оптимальное аэродинамическое сопротивление и достаточно высокую силу тяги. В дальнейшем на основе данных результатов планируется разработка ветроустановки с лопастями в виде вращающихся цилиндров с горизонтальной осью вращения.

\section{Финансирование работы}

Исследование выполнено при поддержки гранта № AР05131520 - Разработка и создание опытного образца ветроэнергетической установки для альтернативного электроснабжения с применением электрогенератора отечественного производства.

\section{Список литературы}

[1] Бычков Н.М. // Теплофизика и аэромеханика. 2008. Т. 15. № 2. C. $583-596$.

[2] Kussaiynov K., Sakipova S.E., Tansykbaeva N.K. // Turbulence, Heat and Mass Transfer: $7^{\text {th }}$ International Symposium (September 24-27). Palermo, 2012. P. 125-128.

[3] Kussayinov K., Shuyushbayeva N.K., Ryzhykh Yu.N., Stepanova Yu.O., Bagdatova S.B. // Bulletin of the Karaganda University Physics Series. 2016. Vol. 82. N 2. P. 50-56.

[4] Кусаиынов К., Танашева Н.К., Тургунов М.М., Алибекова А.P. // ЖТФ. 2015. Т. 85. Вып. 5. С. 23-26. [Kusaiynov K., Tanasheva N.K., Turgunov M.M., Alibekova A.R. // Tech. Phys. 2015. Vol. 60 N 5. P. 656-659. DOI: $10.1134 / \mathrm{S} 1063784215050126]$

[5] Танашева Н.К., Шуюшбаева Н.Н., Мусенова Э.К. // Письма в ЖТФ. 2018. Т. 44. Вып. 17. С. 66-70. [Tanasheva N.K., Shuyushbayeva N.N., Mussenova E.K. // Tech. Phys. Lett. 2018. Vol. 44. N 9. P. 787-789. DOI: $10.1134 / \mathrm{S} 1063785018090134]$ 